\title{
O fazer musical de crianças em experiências de musicalização infantil ${ }^{1}$
}

\author{
Mariane Cristina Souza de Oliveira² \\ Aline Sommerhalder ${ }^{3}$ \\ Ilza Leme Zenker Joly ${ }^{4}$
}

\section{Resumo}

Apresenta resultados de uma pesquisa que abordou fazeres musicais de crianças. Identificou e descreveu o fazer musical de crianças em um Projeto de Musicalização Infantil. Em vertente qualitativa foi realizada em um Laboratório de Musicalização com crianças entre 4 e 9 anos e a equipe de musicalização. Os encontros foram filmados com transcrição e análise qualitativa, à luz do referencial teórico. O corpo, os movimentos, os gestos e as brincadeiras foram as principais formas de concretização dos fazeres musicais. Espera-se colaborar com os estudos no campo da educação musical e fundados no diálogo e na emancipação do humano.

Palavras-chave: Crianças; Educação Musical; Aprendizagem; Lúdico.

\section{Abstract}

\section{The musical action of children in child musicalization experiences}

Presents results from a survey that touched on musical pratices of children. Identified and described the musical making of children in a Children's Musicalization Project. In a qualitative way, it was performed in a Musicalization Laboratory with children between 4 and 9 years old and the musicalization team. The class were filmed with transcription and qualitative analysis, in the light of the theoretical reference. The body, movements, gestures and games were the main forms of musical achievement. It is hoped to collaborate with the studies in the field of musical education and based on the dialogue and the emancipation of the humano.

Keywords: Children; Music Education; Learning;Play.

\section{Introdução}

O artigo em questão origina-se de uma pesquisa concluída que abordou relações de crianças com a música e suas participações em contexto de Musicalização Infantil. Para tanto, considerou-se a criança como sujeito competente, pensante e ativa no processo de ensinar e de aprender. Interessou-se pela escuta de crianças, seus olhares e suas linguagens, especificamente seus fazeres com a experiência musical vivida. O estudo busca fomentar reflexões e produzir conhecimentos sobre o ensino de música para crianças pequenas, visando

\footnotetext{
${ }^{1}$ Pesquisa parcialmente financiada pela Capes.

2 UFSCar. São Carlos/SP. artesoliveria@gmail.com

${ }^{3}$ UFSCar. São Carlos/SP. sommeraline1@gmail.com

${ }^{4}$ UFSCar. São Carlos/SP. ilzazenker@gmail.com
}

Periódico Horizontes - USF - Itatiba, SP - Brasil - e019040 
o oferecimento de melhores experiências musicais e oportunidades educativas emancipadoras.

Estabeleceu-se como questões instigadoras de pesquisa: Que fazer musical é construído por um grupo de crianças provenientes de um Projeto de Musicalização? De que maneira participam da Musicalização Infantil? A pesquisa teve por objetivo identificar e descrever o fazer musical construído por crianças, em experiências proporcionadas da participação em um Projeto de Musicalização Infantil.

As diversas sociedades têm ideias diferentes do que pode ou não ser música, de acordo com o consenso e opinião sobre a forma como esses sons são organizados e suas diferentes funções. A música assume diferentes papéis, podendo ser uma música de celebração, festejo ou acalanto, por exemplo. Isso somente é possível pela experiência comum, de forma que diferentes pessoas sejam capazes de ouvir e reconhecer os padrões musicais que chegam aos seus ouvidos. A música passa a ser considerada por um grupo humano, quando esta se torna familiar.

A familiaridade parte das vivências, pois familiarizamos com certos princípios, organizações sonoras, tornando essa música significativa para cada um/a de nós. Se não nos familiarizamos com determinado tipo de música por ela não fazer parte de nossas experiências, essa música causa estranhamento. Quando a música não faz parte dessas vivências, excedendo as possibilidades de apreensão daqueles que a ouvem, pode se tornar desinteressante ou confusa, causando estranheza. Não podemos afirmar que a música é uma linguagem universal, mas ela está presente nas diversas sociedades como uma linguagem culturalmente construída.

Se a música fosse uma linguagem universal, seria sempre significativa - isto é, qualquer música seria significativa para qualquer pessoa -, independentemente da cultura, e, desse modo, a estranheza em relação à música do outro não existiria (PENNA, 2015, p.24).

Compreendemos que, enquanto fenômeno presente entre todos os grupos sociais e em diferentes tempos, a música é universal, mas como linguagem é culturalmente construída. Se considerarmos a música como uma linguagem socialmente construída e uma forma de comunicação que envolve o contexto, o momento histórico, formas de organização coletiva, 
concluímos que a música, assim como qualquer obra de arte é codificada e a sua apreensão pressupõe o domínio do código.

Portanto, a familiarização somente ocorre por meio do contato e da ação sobre as manifestações artísticas, de forma concreta. No caso da música, esta ocorre por meio da concreticidade sonora. Como a familiaridade depende do contato, do convívio, podemos pensar que nem sempre o acesso é disponibilizado devido às diversas formas de organização da sociedade em que o acesso às linguagens artísticas ainda é restrito a determinados grupos sociais.

Uma das formas de acesso à linguagem musical ocorre com a musicalização, que propõe a sensibilidade ao sonoro, a sua familiarização. Penna (2015) ensina que a musicalização é o ato ou o processo de musicalizar. Sobre isso, Gainza (2002) explica que musicalizar ou musicalizar-se é tornar ou tornar-se sensível à música, de modo que ao ouvi-la, internamente, a pessoa se mova com ela, reaja a ela. A música caracteriza-se por seu caráter comunicativo e expressivo. Expressivo porque objetiva e dá forma a uma vivência humana e, comunicativo ao poder revelar essa experiência pessoal tornando-a possível de compartilhamento, podendo alcançar outras pessoas.

Para que a música seja compartilhada, é preciso que ela seja compreendida, sendo esta compreensão diferente da que se aplica à linguagem verbal, cotidiana. Então, se musicalizar ou musicalizar-se é tornar ou tornar-se sensível à música, podemos perceber que a sensibilidade, assim como a compreensão, tem por base:

Um padrão culturalmente compartilhado para a organização dos sons numa linguagem artística, padrão este que, socialmente construído, é socialmente apreendido - pela vivência, pelo contato cotidiano, pela familiarização -, embora também possa ser apreendido na escola (PENNA, 2015, p.31).

A autora desmistifica o fato de que o "ser sensível a música" cabe apenas a alguém com uma sensibilidade originária de um dom inato. Trata-se de uma sensibilidade adquirida, aprendida, construída em um processo em que, muitas vezes, não é consciente, está contido nas relações compartilhadas em que cada ser tem suas potencialidades (como, por exemplo,

Periódico Horizontes - USF - Itatiba, SP - Brasil - e019040 
sua capacidade de emocionar-se ou discriminar um som), trabalhadas de modo a poder reagir a um estímulo sonoro. Penna (2015) ainda contribui:

[...] musicalizar é desenvolver os instrumentos de percepção necessários para que o indivíduo possa ser sensível a música, apreendê-la, recebendo o material sonoro/musical como significativo. Pois nada é significativo no vazio, mas apenas quando relacionado e articulado ao quadro das experiências acumuladas, quando compatível com os esquemas de percepção desenvolvidas (PENNA, 2015, p.33).

A musicalização, quando orientada, pode oferecer novas experiências de modo que amplie o universo musical daqueles que fazem parte desse processo, aprimorando a percepção, a fim de dar subsídios para a compreensão das diversas linguagens musicais e suas características. Nesse processo, democratiza-se e com isso, possibilita acesso e familiaridade para aqueles que, de alguma forma, foram privados de experiências que proporcionassem o desenvolvimento ou aprimoramento de seus esquemas de apreensão da linguagem musical. Para aqueles que tiveram essa oportunidade, a musicalização orientada poderá proporcionar a expansão e tomada de consciência de seus esquemas de percepção musical.

\section{A musicalização no processo educativo de crianças}

Espera-se que a musicalização possibilite a expressão criativa em que ao apreender a linguagem musical, a pessoa possa levá-la para outros âmbitos de sua vida, outras situações. Ou seja, que a vivência com a musicalização ultrapasse a recepção sonora e possibilite a criação musical, o diálogo e a transformação do material sonoro. Que a pessoa possa recriar a própria música, possuindo-a ativamente ou tendo condições de criticá-la.

[...] a musicalização como um processo educacional orientado que, visando promover uma participação mais ampla na cultura socialmente produzida, efetua o desenvolvimento dos esquemas de percepção, expressão e pensamento necessários à apreensão da linguagem musical, de modo que o indivíduo se torne capaz de apropriar-se criticamente das várias manifestações musicais disponíveis em seu ambiente - o que vale dizer: inserir-se em seu

Periódico Horizontes - USF - Itatiba, SP - Brasil - e019040 
meio sociocultural de modo crítico e participante. Esse é o objetivo final da musicalização, na qual a música é o material para o processo educativo e formativo mais amplo, dirigido para o pleno desenvolvimento do indivíduo, como sujeito social (PENNA, 2015, p. 49).

Com isso, a musicalização proporciona o encontro da pessoa com a essência da música. Musicalizar é dar condições para que a criança compreenda expressivamente e significativamente o que ouve e o que executa musicalmente. É proporcionar as ferramentas básicas para a compreensão e utilização da música como linguagem (CASCARELLI, 2012). Sobre esse aspecto, Brito (2007) complementa que a musicalização é o processo de imersão no ambiente sonoro de forma que a percepção e ação, a prática e a reflexão estejam integradas. Não se trata de uma etapa preparatória para aprender um instrumento posteriormente, por exemplo, e sim de um "agregar de qualidades" em que acontece o processo de fazer e pensar a música, de forma ampla.

Gainza (2002) compreende a musicalização como a possibilidade da expressão criativa de movimento e liberdade, e que deve ser tomada tanto como ponto de partida como ponto de chegada, no desenvolvimento da linguagem musical. De modo que a criança tem a possibilidade de explorar, ampliar e interagir com diversos materiais sonoros, convertendo-se no seu principal promotor da construção de seu mundo interno, em um protagonista de seu próprio desenvolvimento musical e humano.

Com isso, aprende-se música experimentando e fazendo música, de forma que esse fazer passa pelo corpo, pelas nomeações, rotulações musicais, pela grafia e notação, que devem fazer parte da musicalização de forma integral junto com as atividades intuitivas, para possibilitar a autonomia na linguagem musical.

O fazer musical deve estar presente na prática de musicalização, pois este é o modo como recebemos o material sonoro, criamos conexão com ele, apreendemos e significamos a experiência. O fazer musical implica escutar e produzir sons e silêncios, que compõe as diversas estruturas sonoras organizadas nas sociedades,

[...] assim sendo, são singulares e diversos os processos de produção e significação do fazer musical, mesmo que prevaleçam modelos e sistemas Periódico Horizontes - USF - Itatiba, SP - Brasil - e019040 
largamente repetidos e estabilizados no decorrer do tempo, mesmo que estes, na atualidade, sejam reproduzidos largamente pela mídia e ainda que, para muitas pessoas, exista uma única (e restrita) ideia de Música (BRITO, 2007, p.49).

Cabe reforçar que o fazer musical assume particularidades daqueles que o fazem, seja o adulto ou a criança em seus respectivos contextos, experiências, realizações e condições de contato e interação com a música (BRITO, 2007). Assume o seu papel de comunicação, uma vez que podemos transmitir uma ideia musical para alguém, mas este por sua vez, ao ouvi-la, apreende, significa e representa de forma única, uma vez que o fazer musical envolve a leitura de mundo, como o ser se conecta com aquela ideia musical.

Em relação às crianças, destacamos que seu modo de relação com o mundo é via ludicidade, curiosidade e invenção. As crianças são um "outro" que está além de nossa captura, inquieta nossos saberes, nossas conviç̧ões, põe a prova nossas práticas questionando-as. Portanto, pensar a criança como um "outro", diferente de nós, é pensar as inquietações e questionamentos que elas nos suscitam (LARROSA, 2013).

Para este autor, quando compreendemos a criança como "outro", significa não apenas aquilo que sabemos, pois, essa sabedoria nos escapa em contato com a criança, pois ela carrega em si verdades que devemos colocar em escuta. Devemos abrir espaço para acolhê-las e recebê-las. $\mathrm{O}$ autor apresenta duas imagens que olham diferentemente essa criança que se apresenta como "outro":

Uma imagem do totalitarismo: o rosto daqueles que, quando olham para uma criança, já sabem, de antemão, o que veem e o que têm de fazer com ela. A contra imagem poderia resultar da inversão da direção do olhar: o rosto daqueles que são capazes de sentir sobre si mesmos o olhar enigmático de uma criança, de perceber o que, nesse olhar, existe de inquietante para todas suas certezas e seguranças e, apesar disso, são capazes de permanecer atentos a esse olhar e de se sentirem responsáveis diante da sua ordem: deves abrir, para mim, um espaço no mundo, de forma que eu possa encontrar um lugar e elevar a minha voz! (LARROSA, 2013, p. 192).

Em diálogo com Larrosa (2013), Rinaldi apresenta: "cada criança que nasce é um "pode ser" de humanidade, é uma possibilidade, o começo de uma esperança, e é Periódico Horizontes - USF - Itatiba, SP - Brasil - e019040 
profundamente influenciada pelos níveis de percepção, vontade, coragem e política do país que a recebe" (RINALDI, 2012, p.305). As crianças são "um pode ser", ao mesmo tempo que são nosso presente, pois tornam-se sujeitos portadoras de direitos, de valores e de cultura, desde o momento do seu nascimento. Em consonância, Gobbi e Pinnaza (2014) apresentam a criança como um sujeito histórico e social que, ao compartilhar em diferentes contextos de vida, com seus pares e com adultos não somente se apropria, mas também produz cultura.

[...] é considerada um ser ativo, capaz de participar do processo educativo com seus conhecimentos e experiências e de alcançar, progressivamente, a autonomia. Deixa, portanto, de ser pensada como um projeto de homem futuro para ser vista como alguém hoje, ser ativo e sujeito de direitos, bem como de suas ações (GOBBI e PINAZZA, 2014, p. 11).

Nessa perspectiva, Dornelles (2008) aponta que pensar sobre as crianças é pensar diferente do que pensávamos antes. Temos que pensar na criança naquilo que nos incita, nos perturba, nos atormenta, nos cativa e nos marca. Logo, somada a capacidade de mudar a direção do olhar para essas crianças, defendemos a necessária escuta sensível, que propõe Rinaldi (2012). Para a autora, é preciso que a palavra "escutar" deixe de ser apenas uma palavra e se torne uma abordagem sobre a vida, de forma que assim poderemos entender seu significado.

[...] escutar é uma atitude que requer a coragem de se entregar à convicção de que o nosso ser é só uma pequena parte de um conhecimento mais amplo; escutar é uma metáfora para estar aberto aos outros, ter sensibilidade para ouvir e ser ouvido, em todos os sentidos (RINALDI, 2012, p. 208).

Rinaldi (2012) anuncia que "escutar" é uma palavra que não deveria ser dirigida apenas às crianças. Escutar é um ato de dar a si e ao outro o tempo para ouvir. É um ato que abarca desejos, emoções, uma abertura ao diferente. Também é um ato de criação, visto que envolve a interpretação de ambas as partes. É uma tarefa difícil, envolve dar valor ao outro, mesmo que as opiniões sejam divergentes. É necessária a disponibilidade ao outro que também gera mudanças.

Escutar é uma premissa para qualquer relacionamento de aprendizado. É claro que o aprendizado é algo individual, mas também sabemos que é possível Periódico Horizontes - USF - Itatiba, SP - Brasil - e019040 
elevá-lo a um patamar mais alto quando existe a possibilidade de agir e refletir sobre o mesmo. Representar o ato de aprender e ser capaz de dividi-lo com os outros é indispensável para a reflexividade que gera conhecimento. Desse modo, imagens e intenções são reconhecidas pelo sujeito; elas tomam forma e evoluem por meio da ação, da emoção, da expressividade e das representações icônicas e simbólicas. Essa é a base geradora das linguagens, do aprendizado e da criatividade (RINALDI, 2012, p. 208).

Sendo assim, a criança como "outro" exige uma mudança na direção do olhar que mobiliza, suspende, pertuba e supreende nossas certezas sobre elas. A escuta permite-nos então relacionarmos, abrir espaço e tempo para o diferente, para as novas decobertas. Uma escuta atenta que permite a expressão da linguagem, das aprendizagens e da criatividade. Trata-se da busca da compreensão, da procura pelo modo de ver e aprender como a criança investiga, inventa e cria, representa e se manifesta por meio de diversas linguagens.

Gobbi e Pinazza (2014) comparam a criança a um cientista, que frente ao mundo tem uma atitude aberta em que a dúvida e as suspeitas sobre as coisas não se separam em conteúdos, formas ou fragmentos de compreensão. Para as autoras, tudo emerge, criam-se, recriam-se, materializando-se em criações abrangentes, inventivas e motivadoras a partir de danças, sons, cantos, movimentos, desenhos. A vida torna-se um grande novidade a ser descoberta, experimentada e vivida. O pensamento lógico está ao lado, e não acima, da imaginação. A criança passa, então, sem constragimento das experiências e vivências diante da vida às expressões artísticas nas suas mais variadas formas e linguagens, mostrando-nos sua forma singulares de ver o mundo. Para as autoras, as artes tornam-se uma das formas para compreendermos a criança, pois a música, enquanto arte, possibilita o descobrir, o conhecer e comunicar-se sobre a experiência que é estar nesse mundo buscando seu espaço e descobrindo a si mesma.

Na prática da musicalização infantil, o exercício da presente pesquisa foi escutar a criança, considerando-a como sujeito ativo, competente, pensante, que se apropria e produz cultura, portadora de conhecimento que adquire nas interações com o mundo. Quando a criança tem contato com a música, seu modo de ouvi-la, apreendê-la é único e retornará renovada a ideia musical, seja na exploração sonora, em um novo gesto e uma nova forma de 
se expressar como, por exemplo, usando o corpo.

As crianças fazem música sonorizando sensações, percepções, pensamentos...regidos (ainda) pela unidade, pelo todo, pelo sonoro. A experimentação se sobrepõe à técnica dirigida. Fazer música é uma questão de vontade, de desejo, de conquista. Música que é potência de vontade, que aciona, também, o detalhar, a técnica. Com muitas e outras possibilidades, no entanto, para além daquelas que as alturas e durações definidas permitem construir (BRITO, 2007, p. 83).

O fazer musical passa pela experimentação, pela consciência e leitura do mundo em que vivemos. O fazer musical "é umas das formas de manifestação da consciência reconhecendo a sua propriedade de criar conexões, em processos contínuos de dinâmicos" (BRITO, 2007, p.3). Desta forma, o fazer musical das crianças revela como elas percebem, apreendem e se relacionam com os sons, mas também como percebem, apreendem e se relacionam com o mundo que as cerca e que vêm explorando e descobrindo a cada dia (BRITO, 2003).

\section{Caminho metodológico}

Realizou-se uma pesquisa de abordagem qualitativa, na perspectiva anunciada por Minayo (1999) e Bogdan e Biklen (1994). A pesquisa qualitativa objetiva as experiências dos sujeitos que dela participam, o modo como esses interpretam sua experiência e estruturam assim, o mundo em que vivem. O "[...] processo de condução de investigação qualitativa reflete uma espécie de diálogo entre os investigadores e os respectivos sujeitos, dado estes não serem abordados por aqueles de uma forma neutra" (BOGDAN, BIKLEN, 1994, p.51).

Tomou-se ainda a referência de Brandão e Streck (2006) que destacam que a pesquisa deve ser entendida como uma múltipla teia de e entre pessoas que não estabeleça hierarquias, de acordo com os padrões consagrados de ideias preconcebidas sobre o conhecimento e o seu valor. Para esses autores, o objetivo "é a produção de conhecimentos que permitam uma nova leitura ou pronunciação da realidade" (BRANDÃO e STRECK, 2006, p. 270).

A pesquisa de campo foi realizada em um Laboratório de Musicalização, de uma 
Universidade Pública, localizada no estado de São Paulo. O referido Laboratório desenvolve o Projeto de Extensão Universitária Musicalização (desde 1989), com a oferta de experiências musicais para grupos de bebês e crianças da comunidade. Este Laboratório realiza ainda, além da extensão universitária, a pesquisa e a formação de profissionais docentes, em nível superior (de cursos de Licenciatura em Música, Licenciatura em Pedagogia, dentre outros, além de Programas de Pós-Graduação). A presente pesquisa foi realizada em um dos grupos do Projeto de Musicalização, especificamente em uma turma de musicalização infantil, com encontros uma vez por semana (quarta-feira), durante uma hora (das 18 às 19 h), no período de setembro a dezembro, totalizando 12 encontros de coleta de dados.

O Laboratório compreendia uma sala ampla, com piso de madeira, decoração de quadros nas paredes, quadro branco, dois flip-charts e instrumentos musicais, como piano e teclado. Armários guardavam diversos outros instrumentos musicais, brinquedos, livros, almofadas e outros objetos lúdicos. Em um canto, havia mesa com cadeiras para reunião, computador e impressora e sofá, para acolhimento das famílias ou outras pessoas que acompanhavam os encontros. No chão havia um círculo em fita, para delimitação do espaço de atividades dos bebês e das crianças. A sala era bem arejada, com ventiladores, boa iluminação e janelas.

Foram sujeitos da pesquisa dez crianças (sete meninas e três meninos), com idades entre 4 e 9 anos. A maioria das crianças vinha de familiares de servidores da universidade, mas algumas não apresentavam esse vínculo. Muitas já tinham participado de grupos anteriores de musicalização infantil, deste mesmo Projeto e Laboratório. De modo geral, as crianças eram curiosas, gostavam de brincar, eram participativas e presentes nos encontros. Cabe dizer que esta turma de musicalização atendia crianças da faixa etária de 4 a 7 anos e a escolha por esse grupo deu-se em razão da melhor recepção das crianças ao estudo, assim como da equipe de musicalização. No entanto, neste grupo também havia irmãs, sendo que uma menina com 9 anos de idade solicitou participar junto com a irmã, ao invés de ficar aguardando o término do horário, na sala de espera. Por isso, a mesma foi incluída no grupo e não excluída como sujeito de pesquisa.

Também foram considerados sujeitos da pesquisa sete integrantes da equipe de Periódico Horizontes - USF - Itatiba, SP - Brasil - e019040 
musicalização, compondo estudantes de licenciaturas e coordenação do projeto. A equipe organizava, desenvolvia e avaliava os encontros, realizando as práticas musicais com as crianças. Por esse motivo, considerou-se válido a inclusão da equipe na relação de sujeitos da pesquisa.

Todos os preceitos éticos de pesquisa foram respeitados, com a devida autorização da coordenação do Laboratório de Musicalização, aprovação do Comitê de Ética em Pesquisa com Seres Humanos da Universidade, autorização dos familiares, equipe e assentimento das crianças. O assentimento das crianças também foi realizado de acordo com a Resolução 196/96, sendo que as próprias crianças, assim como a equipe, escolheram seus nomes fictícios. Visando a compreensão dos resultados, na seção a seguir, a identificação das crianças será feita pela letra C após o nome fictício, como forma de diferenciar de um membro da equipe.

Foi utilizada a gravação (filmagem) em vídeo (imagem e som) dos encontros de musicalização com esse agrupamento infantil, com câmera filmadora fixada encima do piano, ângulo ${ }^{5}$ com visibilidade mais apropriada do espaço e das pessoas. A filmadora foi ligada antes do início do encontro, gravando a chegada das crianças até o momento da despedida. As filmagens foram transcritas na íntegra, registrando falas, gestos e comportamentos.

Em relação às atividades realizadas nos encontros de Musicalização Infantil, destaca-se que sempre se iniciava com um momento chamado de recepção e acolhimento das crianças, com a oferta de uma caixa de brinquedos. Nesse momento, as crianças chegavam e tinham a sua disposição uma caixa de brinquedos que possibilitava que elas brincassem com as outras crianças e os membros da equipe, com um tempo de duração de 10 minutos. Nesse tempo, elas também podiam experimentar os instrumentos da sala de musicalização, de forma mais livre.

Além do momento de recepção e acolhimento, a estrutura dos encontros foi construída com a oferta de músicas da cultura da infância, atividades de escuta em que foram utilizadas músicas orquestrais e atividades em que as crianças tocaram em conjunto. As músicas da cultura da infância possibilitaram a aproximação dos profissionais com as crianças,

\footnotetext{
${ }^{5}$ A fixação da filmadora nesse local deu-se após sessões de pré-teste realizadas com o objetivo de definição do local mais adequado para permanência desse recurso de coleta de dados.
}

Periódico Horizontes - USF - Itatiba, SP - Brasil - e019040 
geralmente elas continham uma dança, gestos e brincadeiras, além de trabalhar a expressão corporal, o canto e a memória associada aos gestos.

As músicas orquestrais foram utilizadas nas atividades de escuta e expressão corporal, com objetivo de aproximar as crianças dos timbres dos instrumentos, de alguns compositores e posteriormente, da Orquestra da Universidade. Para isso, foram utilizados CDs, livros e músicas executas nos encontros com auxílio da equipe que tocou diversos instrumentos musicais. As práticas em conjunto foram feitas, utilizando tanto as músicas da cultura da infância, como as músicas orquestrais. Com essas práticas, as crianças se aproximaram da leitura de partitura, tocaram alguns instrumentos de pequena orquestra como triângulo, tambor, coco, crótalo e xilofones.

A análise dos dados foi realizada qualitativamente, à luz do referencial teórico escolhido. Tivemos como base a técnica apresentada por Minayo (1996), iniciando por uma primeira leitura do conjunto do material transcrito. Tratou-se de uma leitura em primeiro plano, a fim de que pudéssemos atingir um nível mais profundo de compreensão do material. Posteriormente, percebemos algumas particularidades e características que se repetiam e que começaram a nos servir como pressupostos iniciais para a organização e posterior análise dos resultados, a partir da realização de agrupamentos por diretriz e temas, pelas proximidades. 0 exercício da organização dos dados, para leitura dos resultados deu-se considerando as falas, gestos e comportamentos que foram observados, repetidas vezes, nas transcrições das filmagens.

\section{Resultados e discussão}

O presente artigo traz os resultados da Diretriz de Análise: Aprendizagens com a Música, com três temas: O corpo musical; Passos para a autonomia musical e Prática em conjunto como formação da familiaridade musical.

O primeiro tema: O corpo musical mostrou como, por meio de práticas musicais, as crianças se comunicaram e se expressaram utilizando seus corpos e movimentos para seu fazer musical. A dança, os gestos, os movimentos rítmicos foram as principais formas de fazer 
musical encontrado, nesse agrupamento infantil. Foi destaque ainda a escuta musical presente nos movimentos expressivos destas crianças. Estes resultados emergiram de experiências de escuta, expressão e produção de gestos proporcionados por diversas práticas musicais, vivenciadas na musicalização infantil.

Nos gestos, que envolveram diversas expressões corporais, estavam presentes a espontaneidade e a relação com a música ouvida, que perpassaram pelo corpo e ainda a forma singular que cada criança encontrou para expressar suas ideias musicais. A escuta da música "Cavalgada das Valquírias" foi representativa para este achado de pesquisa. A cada momento foi anunciado às crianças os instrumentos que essas tocariam.

Logo, Melissa(C) começa fazer um gesto com as mãos como se tocasse um instrumento de sopro e Grisela $(C)$ observa, sorri para a menina e começa um gesto similar, mas balançando o corpo de um lado para o outro. Do outro lado da roda, Sofia(C) faz um gesto, mas apoia os braços sobre os joelhos e estica bem os dedinhos, subindo e descendo (Transcrição de vídeo no4).

Em outro encontro foi apresentado às crianças um trecho da 5a Sinfonia de Beethoven, com auxílio de um aparelho de som. A escuta da música também desencadeou gestos e expressões faciais, seguidos de indagações que indicaram como essa escuta estava sendo experienciada pelas crianças:

Quando a música inicia, forte e presente, Grisela (C) abre bem os olhos e leva a mão na boca. Melissa (C) mostra a língua. Alice (C) estende as mãos e pergunta o que é isso? Melissa (C) começa a rir. As outras crianças permanecem quietas ouvindo. Sofia (C) dá um salto e diz "parece assustador"!! e Tom (C) complementa "parece música de fantasma"!. Grisela (C) então encolhe seu corpo e diz "vou me esconder!". A música prossegue, Sofia (C) entra no meio da roda e começa a girar. Tom (C) faz movimentos com as mãos como se estivesse regendo. Grisela (C) levanta junto com Melissa (C) e as duas começam a dançar juntas, como em uma valsa, porém rápida. As meninas riem uma das outras (Transcrição de vídeo no 7).

Além das escutas, algumas práticas musicais incentivaram um fazer musical que se apresentou em pluralidade de gestos se relacionaram com a música proposta. Como exemplo, 
citamos a atividade que utilizou a música "El Rotlletó" ${ }^{6 ", ~ e m ~ q u e ~ c a d a ~ c r i a n c ̧ a ~ f o i ~ c o n v i d a d a ~ a ~}$ inventar um gesto para uma parte da música e as outras experimentaram juntas, o gesto criado.

Grisela (C) faz um movimento com as mãos leves que vão de um lado ao outro do corpo, conforme a leveza da música. Em seguida Sofia(C) dá um salto e apresenta um gesto rápido e expressivo que lembra uma careta, duas mãos no rosto e língua que vai para dentro e para fora da boca. A música reinicia e Alice(C) é chamada para fazer a parte da música que é mais rápida, alegre e dançante. Alice(C) faz um gesto rápido que envolve o corpo todo. $O$ corpo fica durinho no lugar e pende de um lado para o outro, com os ombros subindo e descendo alternadamente. As crianças sorriem e imitam, brincando com o gesto proposto por Alice(C). Em seguida, Melissa(C) faz um movimento de marcha e todos imitam. A música termina (Transcrição de vídeo no 1).

O corpo e os movimentos das crianças estiveram presentes como modos de fazer musical e se relacionaram com as experiências da escuta musical, seja com a expressão a partir da música apresentada e compartilhada com seus pares, por meio de gestos espontâneos e que possibilitou a interação entre as crianças. Nesse sentido, Rinaldi (2012) destaca que o conhecimento perpassa mente e corpo, de forma que estes não estão fragmentados, mas funcionam como uma unidade em constante troca.

Corpo e mente costumam ser considerados como dois organismos separados, quando se refere aos processos cognitivos em geral, de modo que as experiências corporais vão sendo substituídas pelas representações da mente. Assim, Granja (2006) destaca que, frequentemente, menospreza-se "a ideia de que o organismo é inteiro, e que o corpo como a mente interagem simultaneamente com os objetos do mundo" (GRANJA, 2006, p.54). Os dados revelaram que o corpo e a mente estão presentes, dialogando com o mundo e trazendo suas percepções particulares das experiências musicais. Ainda, quando cada criança tem a oportunidade de oferecer um gesto ao grupo e o expressa, a escolha desse gesto passa ser uma forma de demonstrar seu pensamento, seus interesses, satisfações ou insatisfações (RINALDI, 2012).

\footnotetext{
${ }^{6}$ Atividade realizada com a utilização da música em áudio. Disponível em: L'Auditori. El poble de vent i de fusta.
} Periódico Horizontes - USF - Itatiba, SP - Brasil - e019040 
O corpo foi um meio de representação e diálogo musical, um fazer que contemplou a escuta e que encontrou no gesto a forma de expressar as ideias sobre a música. Marques (2014) anuncia que é com o corpo que nos expressamos e que constituímos nossas identidades. O corpo em movimento possibilita comunicação e expressão de modo que não necessitam, necessariamente, da linguagem verbal. Para as crianças, os movimentos corporais são formas de ser e estar no mundo. Por meio deles, elas concretizam seus fazeres musicais, comunicando, seja com gestos longos, lentos, ritmados, rígidos e com os sorrisos e olhares como estão se relacionando com a música e com seus pares.

Os gestos foram utilizados para o compartilhar e para a efetivação das trocas, entre as crianças. Gainza (2002, p.23) destaca que a "imitação de modelos - a aprendizagem de fora para dentro - coexiste e se complementa com os modos lúdicos e criativos, que promovem a aprendizagem de dentro para fora". A capacidade de imitar, se integra na vida cotidiana com as capacidades de produzir, inventar, descobrir e criar, na aprendizagem que se realiza nas trocas e interações humanas. Para esta autora (2002), a educação deve considerar a melhoria das relações de equilíbrio que envolvem aprender olhando e observando o outro, experimentando seus gestos e criando, inventando e produzindo, a partir das trocas e vivências entre as pessoas.

Considera-se que, por meio dos movimentos corporais, as crianças também expressaram emoções a partir das músicas que escutaram, como na escuta de um trecho da 5a Sinfonia de Beethoven. Rinaldi (2012) aponta que as crianças não têm medo de trazer seus sentimentos e emoções relativos ao amor, medo, alegria, desapontamento. Eles estão presentes e devem ser reconhecidos e legitimados, especialmente em uma educação para a sensibilidade. As emoções, segundo a autora, auxiliam as crianças a explorarem o mundo e ajudam a compreender e criar relações. Por este motivo, quando as crianças demonstraram emoções com a música também estavam sendo afetadas e trazendo à tona aquilo que as toca ou que compreendem do mundo. Devemos lembrar que a música pode despertar ótimas emoções, assim como também pode despertar sensações ruins. Por este motivo, é importante reconhecer o que as crianças dizem com seus corpos, como se comunicam e como sentem, como são afetadas, para que na prática pedagógica possamos escolher materiais sonoros que 
cultivem a sensibilidade das crianças (GAINZA, 2002).

Os movimentos corporais que surgiram com as músicas foram reveladores de sensibilidades, com sentimentos, emoções, visto que musicalizar-se é tornar-se sensível a música (GAINZA, 2002). Os resultados mostraram um corpo que se relacionou com a música, que demonstrou ideias e emoções, olhares para conhecer o outro e observá-lo em seus fazeres, corpo que inventou movimentos como forma de interação humana, aprofundando laços afetivos e de amizade, compartilhando ainda modos de ver e compreender a prática musical.

No tema Passos para a autonomia musical, as crianças expressaram fazeres musicais reveladores de conquistas de autonomia, seja por meio de práticas musicais orientadas ela equipe ou em momentos sem a intervenção da equipe. Ou seja, em que as crianças se organizaram para inventar, decidir e demonstrar, espontaneamente, seus fazeres musicais.

As crianças vivenciaram trocas musicais em grupo, de forma que experimentaram experiências de autonomia na criação e compartilhamento de ideias musicais. Os trechos das transcrições trazem cenas em que algumas atividades dirigidas ${ }^{7}$ propiciaram trocas musicais, mas também possibilitaram que as crianças se organizassem espontaneamente para demonstrar e partilhar.

As crianças foram convidadas a realizar uma atividade de experimentação de regência do grupo, composto pelas crianças e equipe da musicalização. Para isso, alguns sinais de regência foram demonstrados previamente, como o sinal de entrada, de término e de direção, para indicar quais instrumentos deveriam ser tocados, em cada momento.

A música inicia e Sofia(C) abre bem os braços e todos tocam. Começa a saltar e de repente, fecha os braços deixando fechados e esticados e passa a olhar para os instrumentos de sopro e corda. Primavera (E) ajuda dando sinal para os tambores pararem. Sofia(C) mantém os braços esticados em direção aos instrumentos e salta de um lado para o outro. Em seguida, dá um salto em direção aos tambores que começam a tocar. Os instrumentos de corda e sopro param. A menina, saltita, gira e mantém os braços esticados em direção aos tambores. A música termina e Primavera (E) diz "ótimo!", a menina sorri e volta pulando para o seu lugar (Transcrição de vídeo nำ4).

\footnotetext{
${ }^{7}$ Atividades dirigidas foram aquelas em que a prática musical surgiu como proposta e orientação da equipe de musicalização.
}

Periódico Horizontes - USF - Itatiba, SP - Brasil - e019040 
Essa cena da transcrição revelou esses primeiros passos de experiência lúdica de reger e conduzir um grupo, musicalmente. A partir dessa atividade, em outras cenas também foi identificado um fazer musical que envolveu a organização e a condução das crianças, de forma espontânea. Por vezes, esses momentos ocorreram antes do início das práticas musicais, em situações de acolhida e integração das crianças nos encontros, quando elas interagiam com objetos lúdicos e pequenos instrumentos musicais, disponibilizados em uma caixa de brinquedos, na chegada para o encontro.

Grisela (C) canta "Mary tinha um carneirinho, um carneirinho, um carneirinho..." Ao ouvir Grisela(C) cantar, Orquídea(C) observa e sorri a menina, balançando seu corpo, então olha para o xilofone e começa a tocar junto com o canto de Grisela(C). Então, enquanto uma canta a outra toca e toca com notas próximas ao canto no rítmo do canto. Mariane(P) então elogia as meninas. Orquídea(C) olha para Grisela(C) e pergunta "Vamos tocar?". Então elas voltam a tocar o xilofone (Transcrição de vídeo no 11).

Mariane(P) e Orquídea(C) tocam o xilofone. Então, com a mão que não está com a baqueta, Grisela(C) faz um gesto de fechar a mão, três vezes. Mariane (P) e Orquídea(C) param de tocar. Então, Grisela(C) olha para Mariane (P) e diz "você tem que tocar mais fraco!", se dirige ao pau de chuva, pega o instrumento e diz "e também tem que tocar esse!" (Transcrição de vídeo no 11).

Ostetto (2013) anuncia que as crianças aprendem nas relações com o mundo, em diferentes momentos do dia, de aula, dos espaços, nas interações com adultos, objetos, outras crianças e adultos. Elas estão em constante aprendizagem e não esperam, passivamente, que um professor indique a hora de aprender, pois aprender é um processo presente nas relações humanas e na interação com os objetos da realidade e, não apenas quando um adulto ensina. Cabe compreender que as crianças são portadoras de um modo próprio de conhecer e expressar-se, que significam a cultura, ao mesmo tempo em que se apropriam desta cultura.

As crianças inventaram gestos de regência e uma maneira própria de conduzir o grupo. Quando se reencontraram no início ou no final do encontro, em que não havia condução da equipe de musicalização, elas exploraram, fizeram escolhas de instrumentos e mostraram iniciativas de tocar e brincar com a música e os materiais sonoros, anunciando algumas pistas Periódico Horizontes - USF - Itatiba, SP - Brasil - e019040 
de autonomia musical que envolveu a criação, experimentação e o compartilhamento com os demais presentes. Entendemos como autonomia, pois envolveu a outra criança, o grupo e a equipe de musicalização, com manifestação de interesse, realização de escolhas e tomada de decisão para interagir com o outro.

As crianças foram, ao longo dos encontros, pronunciando seus interesses, escolhendo, decidindo e produzindo coletivamente música. Conforme Oliveira e Joly (2016), a autonomia vai se construindo ao longo de diversas experiências musicais, das diversas decisões que vão sendo tomadas, de modo que ela não se estabelece instantaneamente. As decisões envolvem "reconhecer o outro, ouvindo, falando, refletindo e criando". (OLIVEIRA e JOLY, 2016, p. 70). Dialogando com os autores, Freire (2002) traz que:

A gente vai amadurecendo todo dia, ou não. A autonomia, enquanto amadurecimento do ser para si, é processo, é vir a ser. Não ocorre em data marcada. É neste sentido que uma pedagogia da autonomia tem de estar centrada em experiências estimuladoras da decisão e da responsabilidade, vale dizer, em experiências respeitosas da liberdade. (FREIRE, 2002, p.41).

Os resultados revelaram pistas para uma autonomia musical, uma vez que a autonomia engloba a escolha, a partir de interesses, por relacionar-se com esse outro, espontaneamente ou a partir de um incentivo, um convite. Foi um processo que aconteceu nas atividades propostas que visavam possibilitar às crianças a experiência de estar à frente do grupo, experimentando, inventando, imaginando, mas que também se fez presente em outros momentos, reconhecido como brincadeiras que também manifestaram o protagonismo, a tomada de decisão e a criação coletiva de uma música, tornando o fazer musical mais rico.

O terceiro tema Práticas em conjunto como formação da familiaridade musical traz os fazeres musicais das crianças na realização das práticas em conjunto, desenvolvidas ao longo dos encontros e que promoveram ainda, o prazer e o interesse por compartilhar música com os familiares. Esses momentos estiveram presentes desde o primeiro encontro.

Em uma das cenas, as crianças estavam divididas em pequenos grupos, com instrumentos musicais diferentes e prestando atenção nas indicações e orientações feitas, antes de iniciar a atividade. Quando a música iniciou, as crianças conseguiram tocar seguindo a 
partitura e ao término da música, Melissa com um sorriso no rosto, disse: "tem que ficar bem bonita, a minha mãe vai gostar" (Transcrição de vídeo no10).

Essa cena mostrou um dos momentos em que as crianças expressaram o interesse em compartilhar com a família ou também expressaram suas emoções, como o prazer de fazer. Retomamos a ideia de Penna (2015) sobre o fazer musical que varia conforme a época histórica e o contexto. Nessa pesquisa, conhecer o fazer musical exigiu uma aproximação sensível e atenta das crianças, a fim de capturar como elas compreenderam o que é a música ou como elas expressaram o seu próprio fazer musical. As suas falas também foram reveladoras de indicadores de como elas estavam vivenciando e reconhecendo a música, além do interesse em compartilhar essa prática musical com seus familiares.

O interesse em compartilhar é um indicativo de que as músicas vivenciadas vão se tornando familiares, compreendendo a característica de linguagem cultural que a música carrega. Ela depende da vivência, das interações promovidas, do reconhecimento daqueles que a praticam e escutam para ser reconhecida enquanto música. Penna (2015) destaca que é a partir das organizações sonoras que são significativas para nós, é que há a familiarização. Quando não há o reconhecimento de algumas organizações sonoras, pois estas não são significativas para a pessoa ou não há compreensão e domínio de sua linguagem, ocorre o estranhamento que pode vir acompanhado da frase "isso não é música!"; expressão que demostra o não reconhecimento da música do outro. Essa característica é o que torna a música uma linguagem cultural que depende das vivências, trocas, experiências com o outro e do compartilhar. Para essa autora, a familiarização somente é possível a partir do contato e da ação concreta com a música, por meio da experiência (PENNA, 1995).

Outra cena também revelou o prazer no fazer musical infantil: No canto em roda "Flor, minha flor", todas as crianças foram convidadas a entrarem na roda e cantarem um verso. Sempre em duplas, para que cantassem juntas, as crianças que foram ao centro deram as mãos e se olharam tentando cantar o verso, enquanto outras formaram a roda e cantaram o coro:

Ana Luiza(C) começa a cantar e Orquídea (C) observa, Mariane(P) se aproxima e acompanha o canto. Ana Luiza(C) segura a mão de Orquídea(C) que começa a cantar junto. Elas voltam para roda e sorriem uma para a outra e todos Periódico Horizontes - USF - Itatiba, SP - Brasil - e019040 
cantam mais uma vez. Quando a música termina, Grisela(C) diz "adorei!" (Transcrição de vídeo no11).

Ao longo dos encontros, as crianças interagiram com essa linguagem, conhecendo músicas do universo da cultura popular e eruditas. Em ambas, esteve presente o prazer e o interesse em demonstrar as conquistas, com o fazer musical concretizado no cantar, tocar e dançar, possibilitando que essas músicas se tornassem significativas para esse grupo de crianças.

A capacidade de compreender a música não acontece devido a um dom inato, mas trata-se de uma aprendizagem e do desenvolvimento do pensar, das oportunidades para experimentar e para sentir, que decorrem da vivência e da interação com a música (PENNA, 1995). São essas experiências constantes e diversas com a música, o que a autora chama de "frequentação"; a experiência constante com as artes, é que promove a capacidade de compreensão, percepção e apreciação das músicas, gerando processualmente a familiarização.

\section{Considerações finais}

Nossas considerações trazem a compreensão de que o fazer musical é contextualizado, pertencente a um momento histórico e um espaço social. Portanto, depende das pessoas que dele fazem parte, o local onde se encontram, quem são essas pessoas, suas experiências musicais e como elas constroem suas ideias de música, em conjunto. Ideia de música que surge do ato de fazer música, de experimentar, de tocar, de decidir o que é significativo para o grupo, de criar familiaridade, de dar os primeiros passos de autonomia e criação. De despertar sentimentos e do prazer da experiência e do interesse em compartilhar com os outros as descobertas e os fazeres.

A diversidade das produções musicais apresenta estruturas sonoras que são organizadas conforme são reconhecidas e experimentadas por aquelas que dela fazem parte. Brito (2007) destaca que o fazer musical não pode ser desvinculado com o todo da cultura, pois este assume particularidades daqueles que o fazem, no caso, essas crianças como protagonistas desse fazer musical.

Periódico Horizontes - USF - Itatiba, SP - Brasil - e019040 
Essa pesquisa revelou um fazer musical pertencente a este grupo, deste contexto e das particularidades da infância, em que o brincar com a música, com o corpo musicalmente e as interações entre pares e com os adultos aconteceram vivamente, nesses encontros.

Gainza (2002) destaca que se aprende música fazendo música, experienciando música. A aprendizagem envolve o fazer musical, de modo que é necessário que esse fazer seja vivido no corpo e no caso das crianças, via lúdico. Os achados da pesquisa mostraram que as crianças se expressaram corporalmente e a escuta musical foi representada por diversos movimentos e gestos. Além disso, as crianças trocaram olhares e sorrisos, expressando emoções e significando essas experiências musicais vividas. Brito (2007) expõe que o fazer musical:

Assume o seu papel de comunicação, uma vez que podemos transmitir uma ideia musical para alguém, mas este por sua vez, ao ouvi-la, apreende, significa e devolve de forma única, uma vez que o fazer musical envolve a leitura de mundo, o como o ser se conecta com aquela ideia musical. (BRITO, 2007, p. 15).

A expressão corporal também foi um fazer musical, pois representou ideias musicais, partindo da escuta ou de atividades propostas com a intenção de experienciar diversas músicas de forma intuitiva, com a utilização de movimentos corporais. O corpo comunicou e foi revelador do modo como cada criança concretizou a sua relação com a música.

Cabe salientar que, quando houve a realização de algum gesto, esse acompanhou a interpretação feita pela criança, em relação à experiência vivida. Nas práticas de escuta também houve observação do outro e experimentação de gestos, com interpretação ou mesmo invenção. Assim, se o fazer musical é o modo como se recebe o material sonoro, que relações são estabelecidas com esse material, a presente pesquisa demonstrou que, para esse grupo, o corpo foi uma forma encontrada para representação de ideias musicais.

O tema Passos para a autonomia musical mostrou a ampliação do fazer musical deste grupo, quando revelou indicadores de autonomia para a expressão musical. Autonomia que nasceu do reconhecimento e interesse por interagir com esse outro, seja a outra criança ou a equipe de musicalização. Um fazer musical que foi construído no convívio e que aconteceu também coletivamente, em diversos momentos dos encontros, tanto em atividades dirigidas, 
quanto na espontaneidade da invenção de brincadeiras.

A espontaneidade das crianças nas brincadeiras manifestaram as experiências vivenciadas nas práticas de musicalização, revelando o quê e como estavam aprendendo música. A busca da autonomia foi desenvolvida com brincadeiras espontâneas em que as crianças vivenciaram uma regência de música, de modo a experimentar a condução musical. Para isso, elas se organizaram, incluíram a equipe, orientaram, regeram e inventaram gestos para a condução das músicas.

O fazer musical é dinâmico e vai sendo construído ao longo das diversas experiências musicais, seja com atividades dirigidas, seja nas brincadeiras espontâneas. Exige o reconhecimento do outro, sua escuta, o diálogo, para que ocorra a criação (OLIVEIRA e JOLY, 2016). Conforme aponta Freire (2002), a autonomia vai se configurando como processo de amadurecimento e acontece ao longo dos encontros, nas trocas, nas opiniões, nos conflitos, nas escolhas e tomadas de decisão.

Além disso, a pesquisa evidenciou um fazer musical também como processo coletivo, em que as crianças foram construindo suas experiências musicais, trazendo consigo suas características próprias, manifestadas em seus gestos e expressões corporais, próprios da sua leitura de mundo, mas que também apareceram na troca com seus pares e com a equipe, na produção coletiva de música. Assim, o espaço da musicalização foi lugar de encontro e de convivência.

Dessas experiências, ficou evidenciado um fazer musical que carregou em si a vontade de compartilhar com os familiares. Este interesse por compartilhar os fazeres trouxe para reflexão a ampliação e a formação de familiaridade com o repertório musical, trabalhado ao longo dos encontros. Repertório que trouxe músicas da cultura popular e músicas eruditas e que, ao passo em que foram vivenciadas e experimentadas, foram sendo consideradas pelo grupo como parte do seu fazer musical, manifestando o interesse por socializá-lo.

O interesse por compartilhar exigiu o reconhecimento, por este grupo, do material sonoro enquanto música pertencente ao seu mundo. Conforme Penna (2015) somente reconhecemos como familiares as organizações sonoras que são familiares a nós. Caso contrário, a falta de experiência ou domínio da linguagem causa estranhamento, dificultando o

Periódico Horizontes - USF - Itatiba, SP - Brasil - e019040 
reconhecimento e familiarização da música vivenciada. Portanto, Penna (1995) aponta que a familiarização somente é possível a partir do contato e da ação concreta com a música, a partir da experiência. Assim, quando as crianças apontaram o interesse por compartilhar com seus pais suas práticas musicais, houve reconhecimento de sua própria prática como uma prática musical que poderia ser compartilhada. Uma prática musical que considera o fazer musical como algo a ser oferecido ao outro, uma vez que ele se torna significativo, adquire sentido e que pode ser dividido com outras pessoas.

Nesse grupo de musicalização infantil, desenvolveu-se um fazer musical contextualizado, em que as crianças foram sujeitos e atores sociais de sua prática musical. $\mathrm{O}$ fazer musical é uma forma de comunicação e essas crianças representaram suas ideias musicais, seja com a exploração sonora, com brincadeiras envolvendo o corpo e gestos. Também foi invenção, uma vez que apareceram na exploração, na observação e imitação, elementos que tornaram única a mensagem, uma vez que quem se expressou, também trouxe sua leitura de mundo. Foi um processo de autonomia quando considera o outro, carrega a individualidade, mas também constrói, organiza e vivencia experiências musicais agregadoras. Assim, o fazer musical teve ainda caráter coletivo, o grupo foi desenvolvendo junto e descobrindo junto, aprendendo uns com os outros suas ideias de música. Ideias que vão constituindo, aos poucos, o domínio da linguagem musical, ampliando repertório e desenvolvendo familiaridade. O fazer musical depende da prática que é significativa para o grupo e, assim, merece ser compartilhado com outros.

Defende-se uma prática musical coletiva humanizadora e para que isso aconteça, a criança, enquanto sujeito ativo que traz consigo diversas experiências, deve ser uma protagonista do processo de ensino e de aprendizagem. Essa prática musical coletiva humanizadora é fundada no diálogo, nas trocas, nas interações e considera os conhecimentos prévios das crianças, ampliando as experiências nos encontros e percebendo que elas ensinam e aprendem continuamente, inclusive com seus pares. O fazer musical não está desvinculado dessas práticas, ele apresenta a leitura de mundo do grupo, ele comunica, compartilha e representa as ideias de música que o grupo trouxe consigo e desenvolveu, ao longo dos encontros de musicalização.

Periódico Horizontes - USF - Itatiba, SP - Brasil - e019040 


\section{HSE HOR IZON TES}

Esperamos que essa pesquisa possa contribuir para o fortalecimento de práticas musicais coletivas com crianças e inspire ações de educação musical fundadas no diálogo, no respeito e na emancipação do humano, considerando que as crianças são sujeitos ativos e pensantes, realizam ricas trocas, aprendem constantemente e possuem um fazer musical alimentado também pelo seu contexto de vida e próprio das infâncias vividas.

\section{Referências}

BOGDAN, Ro.C.; BIKLEN, S. K.. Investigação qualitativa em educação: uma introdução à teoria e aos métodos. Porto: Porto Editora, 1994.

BRANDÃO, C. R.; STRECK, D. R. A pesquisa participante e a partilha do saber: uma introdução. In: BRANDÃO, C. R.; STRECK, D. R. (organizadores). Pesquisa participante: a partilha do saber. Aparecida, SP: Ideias \& Letras, 2006, p.07-20.

BRITO, T. A. Música na educação infantil. São Paulo: Peirópolis, 2003.

BRITO, T. A. Por uma educação musical do pensamento: novas estratégias de comunicação. Doutorado em Comunicação e Semiótica. Pontifícia Universidade Católica de São Paulo, PUC/SP, Brasil, 2007.

CASCARELLI, C. Oficinas de musicalização para educação infantil e ensino fundamental. Cortez Editora. 2012.

DORNELLES, L. V. Infâncias que nos escapam: da criança na rua à criança cyber. 2.ed. Petrópolis, RJ: Vozes, 2008.

FREIRE, P. Pedagogia da esperança: um reencontro com a pedagogia do oprimido. Rio de Janeiro: Paz e Terra, 2002.

GAINZA, V. H. Pedagogía musical: Dos décadas de pensamiento y acción educativa. Buenos Aires: Grupo Editorial Lumen, 2002.

GOBBI, M. A. PINAZZA, M. A. (Orgs.). Infância e suas linguagens. São Paulo: Cortez, 2014.

GRANJA, E. S. C. Musicalizando a escola: música, conhecimento e educação. 2.ed. São Paulo: Escrituras Editora, 2006.

LARROSA, J. Pedagogia Profana: danças, piruetas e mascaradas. Tradução: Alfredo Veiga-Neto.

Periódico Horizontes - USF - Itatiba, SP - Brasil - e019040 
5.ed. Belo Horizonte: Autêntica Editora, 2013.

MARQUES, I. Corpos e danças na educação infantil. In: GOBBI, M A. PINAZZA, M A. (Orgs.). Infância e suas linguagens. São Paulo: Cortez, 2014, p. 15-25.

MINAYO, M. C. (Org.) Pesquisa Social: Teoria, Método e Criatividade. 14. ed. Rio de Janeiro: Vozes, 1999.

OLIVEIRA, P. A. D. e JOLY, I. Z. L. Ensino coletivo de música: aprendendo por meio da convivência. In: JOLY, I. Z. L. e SEVERINO, N. B. (org). Processos educativos e práticas sociais em música: um olhar para a educação humanizadora: Pesquisas em educação musical. Curitiba: CRV, 2016, p. 67-76.

OSTETTO, L. E. Planejamento e prática pedagógica na Educação Infantil: conhecer as crianças, construir diálogos, tecer possibilidades. In: SOMMERHALDER, A (org). A educação infantil em perspectiva: fundamentos e práticas docentes. São Carlos: EdUFScar, 2013, p. 34-45.

PENNA, M. O papel da arte na educação básica. In: PEREGRINO, Y. R. (coord.). Da camiseta ao museu: o ensino das artes na democratização da cultura. João Pessoa: Ed. Universitária/UFPB, 1995. p. 17-22.

Música (s) e seu ensino. 2.ed. Porto Alegre: Sulina, 2015.

RINALDI, C. Diálogos com Reggio Emilia: escutar, investigar e aprender. São Paulo: Paz e Terra, 2012.

Recebido em julho de 2018.

Aprovado em abril de 2019. 